\title{
Mechanical Properties of Cement Mortar: Development of Structure-Property Relationships
}

\author{
Tewodros Tekeste Ghebrab ${ }^{1)}$ and Parviz Soroushian ${ }^{2)}$
}

(Received August 10, 2010, Revised November 5, 2010, Accepted January 24, 2011)

\begin{abstract}
Theoretical models for prediction of the mechanical properties of cement mortar are developed based on the morphology and interactions of cement hydration products, capillary pores and microcracks. The models account for intermolecular interactions involving the nano-scale calcium silicate hydrate (C-S-H) constituents of hydration products, and consider the effects of capillary pores as well as the microcracks within the hydrated cement paste and at the interfacial transition zone (ITZ). Cement mortar was modeled as a three-phase material composed of hydrated cement paste, fine aggregates and ITZ. The Hashin's bound model was used to predict the elastic modulus of mortar as a three-phase composite. Theoretical evaluation of fracture toughness indicated that the frictional pullout of fine aggregates makes major contribution to the fracture energy of cement mortar. Linear fracture mechanics principles were used to model the tensile strength of mortar. The predictions of theoretical models compared reasonably with empirical values.
\end{abstract}

Keyword: structure-property relationships, mechanical properties, cement mortar, ITZ, fine aggregates.

\section{Introduction}

Theoretical models were developed for prediction of the mechanical properties of cement mortar using background models developed for hydrated cement paste. ${ }^{1}$ The paste models account for the intermolecular interactions between nano-scale calcium silicate hydrate (C-S-H) structures, pullout of micro-scale calcium hydroxide $(\mathrm{CH})$ crystals, and the effects of capillary pores and microcracks on lowering the mechanical properties of hydrated cement paste (HCP). ${ }^{1}$ The work reported herein employed these background theoretical models of hydrated cement paste to model the mechanical performance of cement mortar accounting for the effects of fine aggregates, the ITZ, and the shrinkage microcracks developing predominantly at the ITZ.

The ITZ is usually expressed as a region having a thickness of $30-50 \mu \mathrm{m}$, in which the hydrated cement paste composition differs significantly from that of the bulk cement paste. ${ }^{2}$ The ITZ has much higher porosity and $\mathrm{CH}$ volume fraction, and lower contents of C-S-H gel and unhydrated cement paste when compared with the bulk cement paste. This is attributed, to some extent, to the low packing of C-S-H gels near the surface of aggregate particle. ${ }^{2,3}$ The ITZ constitutes the weakest phase of mortar. ${ }^{4}$

\footnotetext{
${ }^{1)}$ Dept. of Construction Engineering, Texas Tech University, Box 4310, Lubbock, TX 79409-3107, USA.

E-mail: tewodros.ghebrab@ttu.edu.

${ }^{2)}$ Dept. Civil and Environmental Engineering, Michigan State University, Room 3546, Engineering Building, East Lansing, MI 48824-1226, USA.

Copyright (c) 2011, Korea Concrete Institute. All rights reserved, including the making of copies without the written permission of the copyright proprietors.
}

\section{Modulus of elasticity of cement mortar}

Cracks propagate in cement mortar mostly through the hydrated cement paste and along the ITZ. This indicates that the ITZ influences the mechanical properties of cement mortar. In modeling the elastic modulus of cement mortar, the effect of ITZ was considered by evaluating mortar as a three-phase composite material.

In order to develop the elastic modulus model of cement mortar, the modulus of elasticity of every constituent phase of the composite material was determined. For hydrated cement paste, the background elastic modulus model (Eq. (1)) was used. The modulus of elasticity of the ITZ in cement mortar $\left(E_{\text {im }}\right)$ is a modified version of the elastic modulus model of hydrated cement paste. The capillary porosity of the ITZ was considered to be about twice that of the bulk hydrated cement paste. The basis for the assumption is that the maximum porosity in ITZ is three times that of cement matrix. ${ }^{5}$ Since the minimum possible porosity in ITZ is the same as that of cement matrix, we have taken the average porosity for ITZ, which is twice that of cement matrix. This variation in porosity was accounted for in developing the elastic modulus of the ITZ $\left(E_{i m}\right)$ based on that of the hydrated cement paste $\left(E_{h}\right)$. The modulus of elasticity of fine aggregates $\left(E_{s}\right)$ ranges from $70 \mathrm{GPa}$ to $90 \mathrm{GPa}^{6}$ A sensitivity analysis was conducted to evaluate the significance of this range in determining the modulus of elasticity of cement mortar.

$$
E_{h}=0.77 E_{o} \frac{\left(1-p_{h}\right)\left(\pi-4 p_{h}\right)^{0.37}}{\left(1+2 \frac{a}{b}\right) p_{h}^{0.37}}
$$

where $E_{h}=$ elastic modulus of hydrated cement paste, $E_{o}=$ intrinsic modulus of elasticity of hydrated cement paste, $a \& b$ are half 
of the major and minor axes lengths of the ellipsoidal capillary pores, respectively, and $p_{h}=$ capillary porosity.

The upper and lower bounds of the modulus of elasticity of cement mortar were calculated from an equation relating the modulus of elasticity of a composite material to its shear modulus $\left(G_{m}^{\prime}\right)$ and bulk modulus $\left(K_{m}^{\prime}\right)$ (Eq. (2)). ${ }^{7}$ The upper and lower bounds of the shear modulus and bulk modulus were calculated using the Hashin's modulus of elasticity model for three-phase composite materials (Eqs. (3)-(7)). ${ }^{7}$ The steps followed for the computation of the upper and lower bounds for the modulus of elasticity of cement mortar are presented below.

The upper and lower bounds of the elastic modulus of mortar, $E_{m}$, were approximated as follows: ${ }^{7}$

$$
\frac{9 K_{m-}^{\prime} G_{m-}^{\prime}}{3 K_{m-}^{\prime}+G_{m-}^{\prime}} \leq E_{m} \leq \frac{9 K_{m+}^{\prime} G_{m+}^{\prime}}{3 K_{m+}^{\prime}+G_{m+}^{\prime}}
$$

where $K_{m+}^{\prime}$ and $K_{m \text { - }}^{\prime}$ are the upper and lower bounds of the bulk modulus of cement mortar, respectively; and $G_{m+}^{\prime}$ and $G_{m \text { - }}^{\prime}$ are the upper and lower bounds of the shear modulus of cement mortar, respectively. These parameters were calculated as follows:

Lower bound of the bulk modulus of cement mortar, $K_{m-}^{\prime}$,

$$
\frac{1}{K_{m-}^{\prime}}=\frac{V_{h}{ }^{\prime}}{K_{h}{ }^{\prime}}+\frac{V_{s}^{\prime}}{K_{s}{ }^{\prime}}+\frac{3 V_{s}^{\prime} t_{r}}{K_{i}^{\prime}+1.33 G_{i}^{\prime}}
$$

where $V_{s}^{\prime}$ is volume fraction of sand, $V_{h}{ }^{\prime}$ is volume fraction of HCP, $K_{s}{ }^{\prime}$ is bulk modulus of sand, $K_{h}{ }^{\prime}$ is bulk modulus of HCP, $K_{i}^{\prime}$ is bulk modulus of ITZ, $G_{i}{ }^{\prime}$ is shear modulus of ITZ, and $\mathrm{t}_{\mathrm{r}}$ is the ratio of the thickness of the ITZ to the radius of an equivalent spherical fine aggregate. All these parameters are defined below. Upper bound of the bulk modulus of cement mortar, $K_{m+}^{\prime}$,

$$
K_{m+}^{\prime}=V_{h}{ }^{\prime} K_{h}{ }^{\prime}+\frac{V_{s}{ }^{\prime} K_{s}{ }^{\prime}}{1+\frac{3 K_{s}{ }^{\prime} t_{r}}{K_{i}{ }^{\prime}+1.33 G_{i}{ }^{\prime}}}
$$

Lower bound of the shear modulus of cement mortar, $G_{m-}^{\prime}$,

$$
\frac{1}{G_{m-}^{\prime}}=\frac{V_{h}{ }^{\prime}}{G_{h}{ }^{\prime}}+\frac{V_{s}{ }^{\prime}}{G_{s}{ }^{\prime}}+0.4 V_{s}{ }^{\prime} t_{r}\left(\frac{2}{K_{i}{ }^{\prime}+1.33 G_{i}{ }^{\prime}}+\frac{6}{G_{i}{ }^{\prime}}\right)
$$

where $G_{h}{ }^{\prime}$ is shear modulus of HCP.

Upper bound of the shear modulus of cement mortar, $G_{m+}^{\prime}$,

$$
G_{m+}^{\prime}=V_{h}{ }^{\prime} G_{h}{ }^{\prime}+\frac{V_{s}{ }^{\prime} G_{s}{ }^{\prime}}{1+\frac{2.5 G_{s}{ }^{\prime} t_{r}}{K_{i}{ }^{\prime}+3.33 G_{i}{ }^{\prime}}}
$$

The next step was to determine all the parameters of the above equations. The bulk modulus and shear modulus of any material are related to its modulus of elasticity through Eqs. (7) and (8): ${ }^{7}$

$$
\begin{aligned}
K^{\prime} & =\frac{E}{3(1-2 v)} \\
G^{\prime} & =\frac{E}{2(1+v)}
\end{aligned}
$$

where $E$ and $v$ are the modulus of elasticity and Poisson's ratio of a material, respectively.

From the above relationships, the bulk modulus and shear modulus of hydrated cement paste and fine aggregates were calculated as follows (considering $v=0.2$ for both the $\mathrm{HCP}^{8}$ and fine aggregates ${ }^{9}$ ):

The bulk modulus of HCP, $K_{h}{ }^{\prime}$,

$$
K_{h}^{\prime}=\frac{E_{h}}{3(1-2 v)}=\frac{E_{h}}{3(1-2(0.2))}=0.56 E_{h}
$$

The bulk modulus of sand (fine aggregate), $K_{s}{ }^{\prime}$,

$$
K_{s}^{\prime}=\frac{E_{s}}{3(1-2 v)}=\frac{E_{s}}{3(1-2(0.2))}=0.56 E_{s}
$$

The shear modulus of HCP, $G_{h}{ }^{\prime}$,

$$
G_{h}^{\prime}=\frac{E_{h}}{2(1+v)}=\frac{E_{h}}{2(1+0.2)}=0.42 E_{h}
$$

The shear modulus of sand (fine aggregate), $G_{s}{ }^{\prime}$,

$$
G_{s}{ }^{\prime}=\frac{E_{s}}{2(1+v)}=\frac{E_{s}}{2(1+0.2)}=0.42 E_{s}
$$

Based on the above relationships, the bulk modulus and the shear modulus of the ITZ of cement mortar could also be determined as follows:

$$
\begin{aligned}
& K_{i}{ }^{\prime}=0.56 E_{i} \\
& G_{i}{ }^{\prime}=0.42 E_{i}
\end{aligned}
$$

with the elastic modulus of sand $\left(E_{s}\right)$ ranging from 70 to $90 \mathrm{GPa}$, the corresponding values of $K_{s}{ }^{\prime}$ and $G_{s}{ }^{\prime}$ range from 39.2 to 50.4 and 29.4 to 37.8 , respectively. A sensitivity analysis conducted to assess the significance of these ranges in determining the mechanical properties of mortar is presented below. The elastic modulus of the ITZ $\left(E_{i}\right)$ is a function of the elastic modulus $\left(E_{h}\right)$ and the capillary porosity $\left(P_{h}\right)$ of the hydrated cement paste in cement mortar. The ratio of the thickness of the ITZ to the radius of an equivalent spherical fine aggregate, $\mathrm{t}_{\mathrm{r}}$, can be expressed as follows: ${ }^{7}$

$$
t_{r}=\frac{t_{i}}{r_{s}}
$$

where $t_{i}$ is thickness of the ITZ which is a function of aggregate size; and $r_{s}$ is the radius of an equivalent spherical aggregate. Thickness of ITZ $\left(t_{i}\right)$ is proportional to the size of the aggregate it envelopes. ${ }^{7}$ It can thus be approximated using the reported values of the maximum ITZ thickness in concrete. A linear relationship was assumed between the aggregate size and the thickness of the ITZ using a size range of 0.1 to $4 \mathrm{~mm}$ and 4 to $25 \mathrm{~mm}$ for fine and coarse aggregates, respectively. The maximum thickness of the ITZ in concrete is about $50 \mu \mathrm{m} .{ }^{2,10}$ This thickness was considered to correspond to a $25 \mathrm{~mm}$ aggregate size. No ITZ was assumed to occur for an aggregate size lower than $0.1 \mathrm{~mm}$. The value of $t_{i}$ was 
thus considered to ranged from 0 to $3.9 \mu \mathrm{m}$ for aggregate size ranging from 0.1 to $4 \mathrm{~mm}$. A sensitivity analysis was conducted to investigate the significance of this range in determining the mechanical properties of mortar, and the results are presented in the next section.

The significance of the three phases in determining the mechanical properties of cement mortar also depends upon their respective volume proportions in the mortar. The calculation of the volume fractions of hydrated cement paste $\left(V_{h}{ }^{\prime}\right)$, fine aggregate $\left(V_{s}^{\prime}\right)$ and ITZ $\left(V_{i}^{\prime}\right)$ in cement mortar is presented below. Since the maximum porosity of ITZ $\left(P_{i}\right)$ is three times ${ }^{11}$ and the minimum is equal to that of cement matrix, an average porosity of ITZ of about twice that of the HCP was assumed.

When very large volume fractions of sand are used in cement mortar, the workability of the fresh mix tends to deteriorate. This damage to workability results in the formation of large voids and micro-defects, which would undermine the performance of mortar. A reasonable range for the volume fraction of sand considered in this investigation is from 0.5 to 0.6 . A mortar mix proportion, where sand and bulk hydrated cement paste constitute $55 \%$ and $45 \%$, respectively, of the mortar volume was considered to represent conventional mortar mixtures. The volume of the ITZ surrounding a single sand particle in cement mortar $\left(V_{l i}\right)$ was calculated using Eq. (16) based on the relationship between aggregate size and the ITZ discussed above. A circular cylinder with aspect (height-to-diameter) ratio equal to 1 was considered as a geometric model of sand (Fig. 1).

This geometric model implies that:

$$
V_{1 i}=2 \pi\left(\left(r_{s}+t_{i}\right)^{3}-r_{s}^{3}\right)
$$

Assuming a uniform aggregate size, the number of sand particles per unit volume of cement mortar $\left(N_{s}\right)$ can be calculated as follows:

$$
N_{s}=\frac{V_{s}}{V_{1 s}}=\frac{V_{s}}{2 \pi r_{s}^{3}}
$$

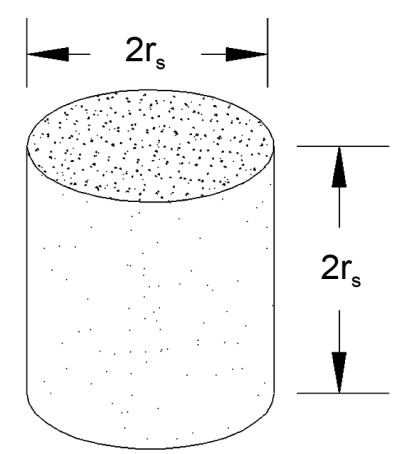

Fig. 1 The geometric model of a sand particle. where $V_{1 s}$ is the volume of a single cylindrical sand particle of radius $r_{s}$ and height $2 r_{s}$ as shown in Fig. 1.

The total volume of the ITZ $\left(V_{i}\right)$ can then be calculated as the product of $N_{s}$ and $V_{l i}$, as follows:

$$
V_{i}=V_{1 i} \times N_{s}
$$

Since $t_{i}$ is proportional to $r_{s}$, for a constant $V_{s}, V_{i}^{\prime}$ and $V_{h}{ }^{\prime}$ remain constant with a change in aggregate size, as shown in Table 1.

\section{Sensitivity analysis of the effect of the fine aggregate elastic modulus on the modulus of elasticity of cement mortar}

Since the elastic modulus of the fine aggregates used in cement mortar ranges from $70 \mathrm{MPa}$ to $90 \mathrm{MPa}$, a sensitivity analysis was conducted to assess the significance of this range of aggregate elastic modulus in determining the modulus of elasticity of cement mortar. In this sensitivity analysis, viable ranges of hydrated cement paste properties were considered (for example, $E_{o}$ equal to $38 \mathrm{GPa}$, and capillary pore aspect ratio, $\mathrm{a} / \mathrm{b}$, equal to 2 ). Based on the results presented in Table 1 , the values of $V_{h}{ }^{\prime}=0.443$, $V_{i}^{\prime}=0.007$ and $V_{s}{ }^{\prime}=0.55$ were considered for evaluation of the elastic modulus of cement mortar. The elastic modulus of hydrated cement paste was calculated by substituting the above values into Eq. (1), and simplifying it to obtain:

$$
E_{h}=5.852\left(1-p_{h}\right) \frac{\left(\pi-4 p_{h}\right)^{0.37}}{p_{h}^{0.37}}
$$

where $\mathrm{E}_{\mathrm{h}}$ and $\mathrm{p}_{\mathrm{h}}$ are the modulus of elasticity and capillary porosity of HCP, respectively.

The modulus of elasticity of the ITZ was calculated by modifying Eq. (19), assuming that $P_{i}$ is twice that of the HCP. ${ }^{5}$ The value of the elastic modulus of the ITZ $\left(E_{i}\right)$ was multiplied by a factor of 0.75 to account for the $25 \%$ volume fraction of the directionally oriented $\mathrm{CH}$ crystals in the transition zone.

$$
E_{i}=3.4\left(1-2 p_{h}\right) \frac{\left(\pi-8 p_{h}\right)^{0.37}}{p_{h}^{0.37}}
$$

$E_{h}$ and $E_{i}$ were calculated using Eqs. (19) and (20) for a reasonable range of capillary porosity in cement mortar. Three aggregate sizes $(0.6,2.3$ and $4 \mathrm{~mm}$ ) were considered to investigate the influence of the variation in aggregate size, and the results suggested that the upper and lower bounds of shear modulus and bulk modulus of mortar did not change considerably with aggregate size. The reason for this is that the bulk modulus and the shear modulus of a material depend upon the volume fractions and elastic moduli of the individual phases in the composite material and not on the

Table 1 Volume fractions of the ITZ and the hydrated cement paste for different aggregate sizes (at constant aggregate volume) in cement mortar.

\begin{tabular}{c|c|c|c|c|c|c}
\hline$r_{s}(\mathrm{~m})$ & $t_{i}(\mathrm{~m})$ & $t_{r}$ & $V_{l i}\left(\mathrm{~m}^{3}\right)$ & $N_{s}$ & $V_{i}{ }^{\prime}$ & $V_{h}{ }^{\prime}$ \\
\hline \hline $0.30 \mathrm{E}-03$ & $1.20 \mathrm{E}-06$ & $4.00 \mathrm{E}-03$ & $2.04 \mathrm{E}-12$ & $3.24 \mathrm{E}+09$ & 0.007 & 0.443 \\
\hline $1.20 \mathrm{E}-03$ & $4.80 \mathrm{E}-06$ & $4.00 \mathrm{E}-03$ & $1.31 \mathrm{E}-10$ & $5.07 \mathrm{E}+07$ & 0.007 & 0.443 \\
\hline $2.00 \mathrm{E}-03$ & $8.00 \mathrm{E}-06$ & $4.00 \mathrm{E}-03$ & $6.06 \mathrm{E}-10$ & $1.09 \mathrm{E}+07$ & 0.007 & 0.443 \\
\hline
\end{tabular}


aggregate size. While the aggregate surface area decreases with increasing aggregate size, the volume fraction of the ITZ remains constant as the aggregate size changes because its thickness increases with aggregate size.

The upper and lower bounds of the elastic modulus of cement mortar $\left(E_{m+}\right.$ and $\left.E_{m-}\right)$ for different elastic moduli of fine aggregates were calculated using Eq. (2). The results are shown in Fig. 2 in order to assess the influence of the variation in the fine aggregate elastic modulus $\left(E_{s}\right)$ on the modulus of elasticity of mortar $\left(E_{m}\right)$. It can be observed in Fig. 2 that the variations in the upper bound of $E_{m}$ tend to be more pronounced when compared with those in the lower bound. However, it could be generally noted that the effect of the variation in the fine aggregate elastic modulus, within the given range, on the elastic modulus of cement mortar is not of great significance. Based on this observation, an average value for the elastic modulus of fine aggregate, $80 \mathrm{GPa}$, was considered as a representative value in development of the model.

Once the upper and lower bounds of the elastic modulus of cement mortar were established, the next step was to develop a reasonable model for the modulus of elasticity of cement mortar, within these bounds. For this purpose, the predictions of an empirical model of elastic modulus, ${ }^{12}$ which was based on substantial experimental data, are compared with the theoretical predictions of lower and upper bounds in Fig. 2. This comparison suggests that the empirical values (reflecting experimental results) fall within the upper and lower bounds of the theoretical model, leaning more towards the lower bound. Based on this observation, the lower-bound model of elastic modulus was considered to reasonably represent the elastic modulus of cement mortar. The modulus of elasticity of cement mortar was thus represented as follows:

$$
E_{m} \approx \frac{9 K_{m-}^{\prime} G_{m-}^{\prime}}{3 K_{m-}^{\prime}+G_{m-}^{\prime}}
$$

With an aggregate elastic modulus $\left(E_{S}\right)$ of $80 \mathrm{GPa}$, Eq. (21) yields the following expression for the modulus of elasticity of cement mortar in terms of the elastic modulus of hydrated cement paste.

$$
E_{m} \approx \frac{5.78 E_{h}^{2}-28.35 E_{h}}{0.04 E_{h}^{2}+2.43 E_{h}-12.46}
$$

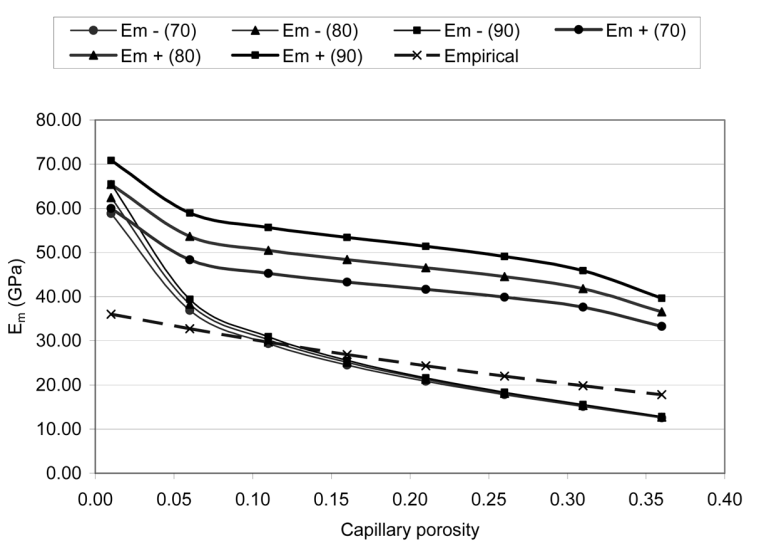

Fig. 2 Comparison of the predictions of theoretical model for the elastic modulus of cement mortar with those of an empirical model based on substantial test data. where $E_{h}$ is the modulus of elasticity of hydrated cement paste, given by Eq. (1).

\section{Mechanistic model for the fracture toughness of cement mortar}

It was noted earlier that major contributions are made to the fracture energy of HCP by the pull-out of $\mathrm{CH}$ crystals. In the case of cement mortar, one should add the contributions of the sand (fine aggregate) pull-out to fracture energy. The pull-out of fine aggregates is expected to make major contributions to fracture toughness by increasing the surface area involved in frictional pull-out. Sand particles are assumed to have rough surfaces, with HCP interacting with sand particles as shown in Fig. 3. Fine aggregates also offer a crack-shielding effect which enhances the process zones in front of the crack tip, and thus contributes to fracture toughness.

Pull-out of sand particles would involves phononic friction as the dendrites of HCP bonding to the sand surface shear off (Fig. 3 ). It is assumed that each dendrite of HCP is subjected to a shearing force by the dendrites on the sand surface, acting at the median contact point. This causes a diagonal tensile stress on the hydrated cement paste dendrite, generating a 45-degree diagonal crack shown in Fig. 4. The surface area of the hydrated cement paste subjected to this stress condition was approximated to be half the pulled-out surface area of sand.

The surface area of sand subjected to pull-out (after debonding) was computed by assuming a cylindrical model of sand shown in Fig. 5. The shaded region in Fig. 5 is the mean surface area of sand subjected to frictional pull-out. This region is assumed to occur, on the average, at the lower quarter of the cylinder height.

\section{Energy released during debonding of sand particles from hydrated cement paste}

The interfacial surface area of sand that is subjected to debonding (followed by pull-out), $A_{s d}$, can be expressed as follows:

$$
A_{s d}=2 \pi r_{s}^{2}
$$

where $A_{s d}$ is interfacial surface are of sand, and $r_{s}$ is the radius of sand particle.

In order to account for the porosity of the ITZ (assumed to be

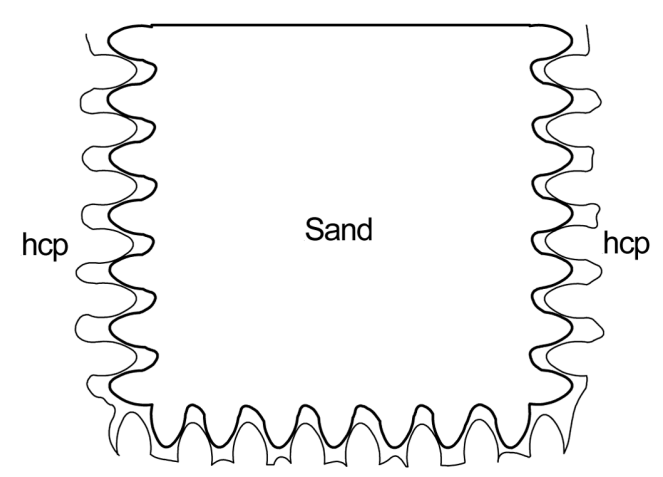

Fig. 3 Surface roughness of fine aggregate, and interaction of the hydrated cement paste (HCP) at the interface. 


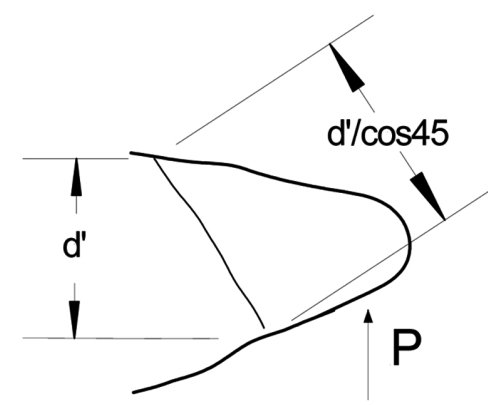

Fig. 4 The crack pattern of the HCP dendrite under the force $\mathrm{P}$ generated during sand pull-out.

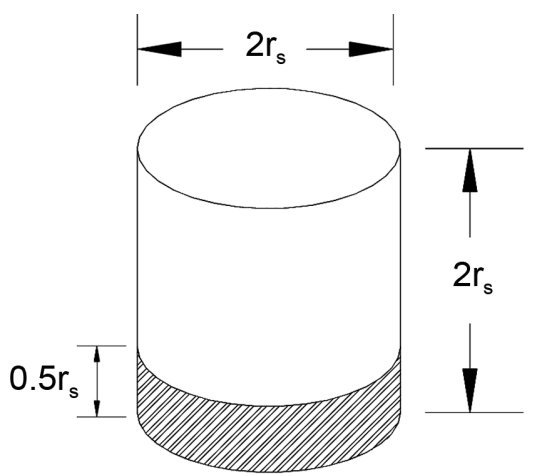

Fig. 5 Surface of sand particle (shaded area) subjected to frictional pull-out.

twice that of HCP, $\mathrm{P}_{\mathrm{h}}$ ), Eq. (23) was further modified as follows:

$$
A_{s d}^{\prime}=2 \pi r_{s}^{2}\left(1-2 P_{h}\right)
$$

Debonding of sand occurs essentially through cracking of the interface zone, and involves debonding of C-S-H globules. The energy lost due to debonding of C-S-H globules is about $1.56 \mathrm{~J} /$ $\mathrm{m}^{2}$. Therefore, the energy released $\left(U_{s d}\right.$, Joules) due to the debonding of sand from HCP (i.e., due to debonding of C-S-H globules in the ITZ) can be calculated as follows:

$$
\begin{aligned}
& U_{s d}=1.56 A_{s d}^{\prime} \\
& \Rightarrow U_{s d}=3.12 \pi r_{s}^{2}\left(1-2 P_{h}\right)
\end{aligned}
$$

The fracture energy released per unit area of $\operatorname{mortar}\left(G_{s d}, \mathrm{~J} / \mathrm{m}^{2}\right)$, due to C-S-H/C-S-H debonding, can be calculated as the total debonding energy released due to one sand particle divided by the projected area of sand on a plane perpendicular to the pull-out direction (see Eqs. (27) and (28)).

$$
\begin{aligned}
& G_{s d}=\frac{3.12 \pi r_{s}^{2}}{\pi r_{s}^{2}}\left(1-2 P_{h}\right) \\
& \Rightarrow G_{s d}=3.12\left(1-2 P_{h}\right)
\end{aligned}
$$

where, $G_{s d}$ is fracture energy $\left(\mathrm{J} / \mathrm{m}^{2}\right)$ released per unit area of mortar due to C-S-H/C-S-H debonding.

\section{Energy released during pull-out of sand particles from hydrated cement paste}

The surface area of sand subjected to frictional pull-out $\left(A_{s p}^{\prime}\right)$ is the shaded area shown in Fig. 5 (excluding the bottom surface):

$$
A_{s p}^{\prime}=\pi r_{s}^{2}\left(1-2 P_{h}\right)
$$

When the dendrites of hydrated cement paste shear off due to sand pull-out, the diameter of fractured dendrites is about $1.414 d^{\prime}$ (due to the diagonal shear effect), as shown in Fig. 4. Due to the assumption that the dendrites of both the hydrated cement paste and the sand are interlocked (Fig. 3), the total surface area of HCP subjected to shear stress $\left(A_{s p h}^{\prime}\right)$ is about 1.414 times $A_{s p}^{\prime}$. Therefore,

$$
A_{s p h}^{\prime}=1.414 \pi r_{s}^{2}\left(1-2 P_{h}\right)
$$

The energy $\left(U_{\text {chspl }}\right)$ released due to $\mathrm{CH}$ pull-out upon interfacial fracture over $A_{s p h}^{\prime}$ can be calculated as the product of $G_{p}$ and $A_{s p h}^{\prime}$ (Eq. (31)), where $G_{p}$ is the energy released per unit fractured surface area (due to $\mathrm{CH}$ pull-out in hydrated cement past), and is considered to be equal to $27.88 \mathrm{~J} / \mathrm{m}^{2}$.

$$
\begin{aligned}
& U_{c h s p 1}=27.88 A_{s p h}^{\prime} \\
& \Rightarrow U_{c h s p 1}=39.42 \pi r_{s}^{2}\left(1-2 P_{h}\right)
\end{aligned}
$$

where $A_{s p h}^{\prime}$ is the total surface area of HCP subjected to shear stress; and $U_{\text {chspl }}$ is the energy released due to $\mathrm{CH}$ pull-out upon interfacial fracture.

Let $U_{\text {chsp } 2}$ represent the energy released due to $\mathrm{CH}$ pull-out at the bottom surface of sand particle. It can be calculated as the product of $G_{p}$ and the base area of the model sand particle shown in Fig. 5:

$$
U_{c h s p 2}=27.88 \pi r_{s}^{2}\left(1-2 P_{h}\right)
$$

The total energy released due to $\mathrm{CH}$ pull-out during the pull-out of sand particles from HCP $\left(U_{c h s p}\right)$ is, therefore, the sum of $U_{c h s p 1}$ and $U_{c h s p 2}$ :

$$
\begin{aligned}
& U_{c h s p}=U_{c h s p 1}+U_{c h s p 2} \\
& U_{c h s p}=67.3 \pi r_{s}^{2}\left(1-2 P_{h}\right)
\end{aligned}
$$

where $U_{\text {chsp }}$ is the total energy released due to $\mathrm{CH}$ pull-out during the pull-out of sand particles from HCP.

The energy released per unit fractured area of ITZ $\left(G_{c h s p}\right.$, in J/ $\mathrm{m}^{2}$ ), due to $\mathrm{CH}$ pull-out, can be calculated as the total energy released as one sand particle pulls out divided by the projected area of the sand on a plane perpendicular to the pull-out direction:

$$
\begin{aligned}
& G_{c h s p}=\frac{67.3 \pi r_{s}^{2}\left(1-2 P_{h}\right)}{\pi r_{s}^{2}} \\
& \Rightarrow G_{c h s p}=67.3\left(1-2 P_{h}\right)
\end{aligned}
$$


where $G_{c h s p}$ is the total energy per unit fractured area released during $\mathrm{CH}$ pull-out from HCP.

The total energy release rate per unit fractured area of the ITZ in $\operatorname{mortar}\left(G_{i m}\right)$ can now be calculated as the sum of $G_{c h s p}$ and $G_{s d}$ :

$$
\begin{aligned}
& G_{i m}=G_{c h s p}+G_{s d} \\
& \Rightarrow G_{i m}=70.4\left(1-2 P_{h}\right)
\end{aligned}
$$

The other factor which contributes to the fracture toughness of cement mortar is the shielding effect of sand particles against crack growth. This crack shielding effect results from bridging of the two crack surfaces by sand particles near the crack tip. This phenomenon promotes multiple microcracking ahead of the crack tip in hydrated cement paste. The region where these microcracks form is called the crack process zone. For typical volume fractions of sand used in mortar, formation of the process zone further increases the fracture toughness of hydrated cement paste by about $65 \%$. Therefore, with a total fracture toughness of hydrated cement paste $\left(G_{o}\right)$ of $29.44 \mathrm{~J} / \mathrm{m}^{2}$, the modified fracture toughness of hydrated cement paste in mortar will be about $1.65 \times 29.44=$ $48.58 \mathrm{~J} / \mathrm{m}^{2}$.

Fracture toughness of mortar $\left(G_{m}\right)$ can now be calculated as the sum of the fracture toughness of the ITZ and that of HCP, proportional to their respective volume fractions in cement mortar:

$$
G_{m}=G_{i m} V_{s}^{\prime}+G_{h} V_{h}^{\prime}
$$

where $V_{s}^{\prime}$ is the sand (and the small ITZ) volume fraction in mortar; and $V_{h}^{\prime}$ is the hydrated cement paste volume fraction in mortar. As noted in previous sections, $V_{s}^{\prime}=0.557$ and $V_{h}^{\prime}=0.443$ are used as reasonable examples. It can also be shown that $G_{h}=G_{o}(1-$ $P_{h}$ ) and $G_{o}=48.58 \mathrm{~J} / \mathrm{m}^{2}$. Substituting these values into Eq. (40) yields:

$$
\begin{aligned}
& G_{m}=70.4\left(1-2 P_{h}\right)+21.38\left(1-P_{h}\right) \\
& \Rightarrow G_{m}=91.78\left(1-1.75 P_{h}\right)
\end{aligned}
$$

The fracture toughness calculated using this model with reasonable capillary porosity $\left(\mathrm{P}_{\mathrm{h}}\right)$ levels ranges from 44 to $76 \mathrm{~J} / \mathrm{m}^{2}$ (Fig. 6), which is in conformance with the experimental values of

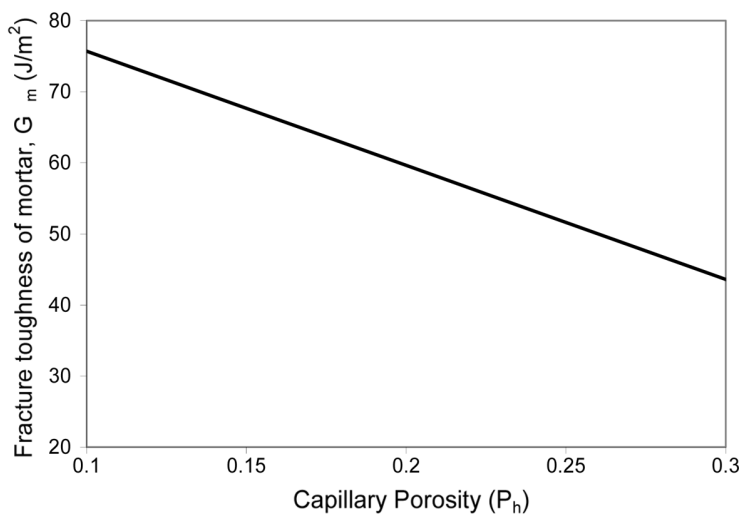

Fig. 6 Fracture toughness of mortar as a function of the capillary porosity of HCP. the fracture toughness of cement mortar which range from 55 to $75 \mathrm{~J} / \mathrm{m}^{2} \cdot{ }^{13}$

A sensitivity analysis was conducted using the theoretical model in order to assess the significance of sand volume fraction in determining the fracture toughness of cement mortar. The relationships between the fracture toughness of mortar $\left(G_{m}\right)$ and the volume fraction of sand $\left(V_{s}^{\prime}\right)$ for capillary porosities $\left(P_{h}\right)$ of 0.3 is plotted in Fig. 7 (for the typical conditions introduced earlier). The increase in sand volume fraction within practical ranges is observed to produce a minor rise in the fracture toughness of cement mortar. Similar trends were observed at other levels of capillary porosity. It should be noted that the addition of sand markedly increases the fracture toughness of cement mortar over that of neat cement paste.

\section{Tensile strength model of cement mortar}

The tensile strength model of cement mortar was developed by applying the Griffith equation:

$$
\sigma_{m t}=\sqrt{\frac{E_{m} G_{m}}{\pi l_{m}}}
$$

where $E_{m}$ is the modulus of elasticity of cement mortar; $G_{m}$ is the fracture toughness of cement mortar; and $l_{m}$ is half the critical crack length at which unstable crack propagation occurs in mortar. Many microcracks form in cement mortar prior to any loading due to the restrained shrinkage effect. The restraint of drying shrinkage partly results from the presence of the dimensionally stable and high-modulus aggregates within the cement paste. Microcracks tend to initiate at the ITZ, and then propagate into the hydrated cement paste. These cracks may extend over and bridge between two adjacent sand particles. ${ }^{3,14}$ In this research, the critical crack length in cement mortar is considered to extend between two sand particles, as shown in Fig. 8.

The initial crack length in mortar $\left(21_{\mathrm{m}}\right)$ can be estimated using Fig. 8 as the sum of the center-to-center distance between two sand particles $\left(l{ }^{\prime \prime}\right)$ and the size of sand $\left(2 \mathrm{r}_{\mathrm{s}}\right)$ :

$$
2 l_{m}=\left(l^{\prime \prime}+2 r_{s}\right)
$$

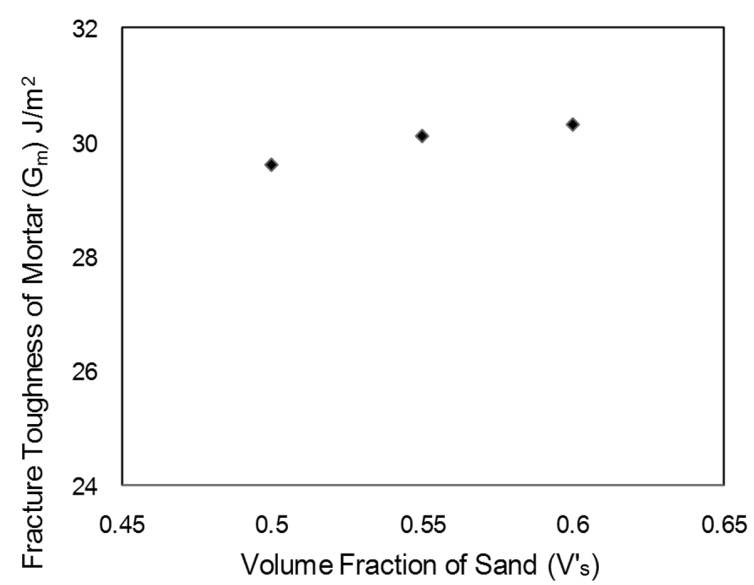

Fig. 7 Fracture toughness of mortar as a function of the volume fraction of sand for a capillary porosity of 0.3 . 


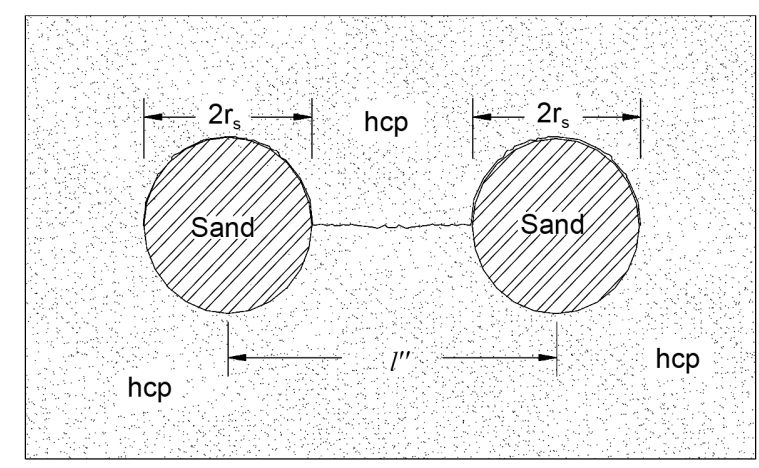

Fig. 8 The critical shrinkage crack in cement mortar bridging between two adjacent sand particles.

Shrinkage cracks are more likely to occur around larger aggregates because their interfaces are weaker (due to attraction of greater quantities of bleeding water) and also because the restrained shrinkage stresses tend to be greater in their vicinity. For this reason, the aggregate size in mortar where crack is likely to initiate was considered to be $4 \mathrm{~mm}$ (i.e., close to the upper bound of fine aggregate particle size). If we assume a uniform sand particle size in cement mortar, the center-to-center spacing of sand particles ( $l$ ") can be calculated for a sand volume fraction of 0.55 as:

$$
\Rightarrow 2 \pi r_{s}^{3}=0.55 l^{\prime \prime}
$$

For a $4 \mathrm{~mm}$ diameter sand,

$$
l^{\prime \prime}=\left(\frac{2 \pi(2)^{3}}{0.55}\right)^{\frac{1}{3}}=4.50 \mathrm{~mm}
$$

Substituting the result of Eq. (46) into Eq. (44) yields $l_{m}=$ $4.24 \mathrm{~mm}$.

The tensile strength model of cement mortar was then obtained by substituting Eqs. (22), (42) and (44), for $E_{m}, G_{m}$ and $l_{m}$, respectively, into Eq. (43). The resulting model is shown below.

$$
\sigma_{m t}=28.9\left[\frac{\left(1-1.75 P_{h}\right)\left[1.2 \beta^{2}-\beta\right]}{\beta^{2}+10.4 \beta-9.23}\right]^{1 / 2}
$$

where $P_{h}$ is the capillary porosity of hydrated cement paste; and $\beta$ is defined as:

$$
\beta=\alpha\left(1-P_{h}\right)
$$

and $\alpha$ is defined as:

$$
\alpha=\left(\frac{\pi-4 P_{h}}{P_{h}}\right)^{0.37}
$$

The relationship between the tensile strength of cement mortar $\left(\sigma_{m t}\right)$ and the porosity of $\mathrm{HCP}\left(P_{h}\right)$ (Eq. (47)) is plotted in Fig. 9. The prediction of the model is compared with experimental results.

A sensitivity analysis was conducted to investigate the effect of sand volume fraction on the tensile strength of cement mortar. Fig. 10 shows the relationships between the tensile strength of cement mortar $\left(\sigma_{m t}\right)$ and the volume fraction of sand $\left(\bar{V}_{s}\right)$ for a typical

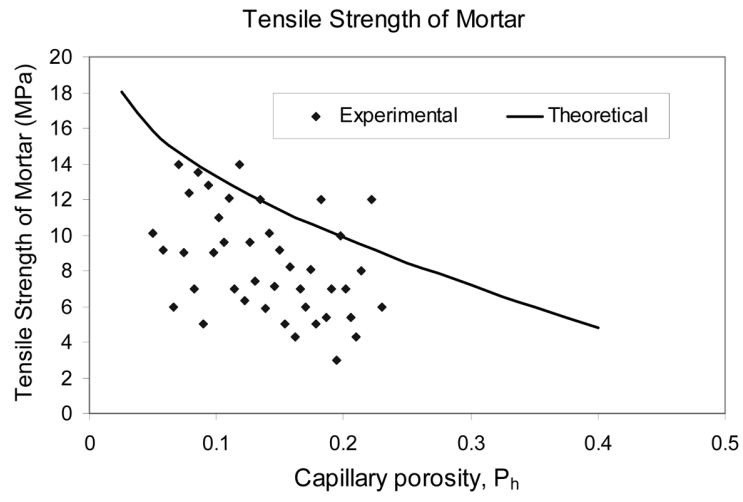

Fig. 9 Tensile strength of cement mortar as a function of the capillary porosity of HCP.

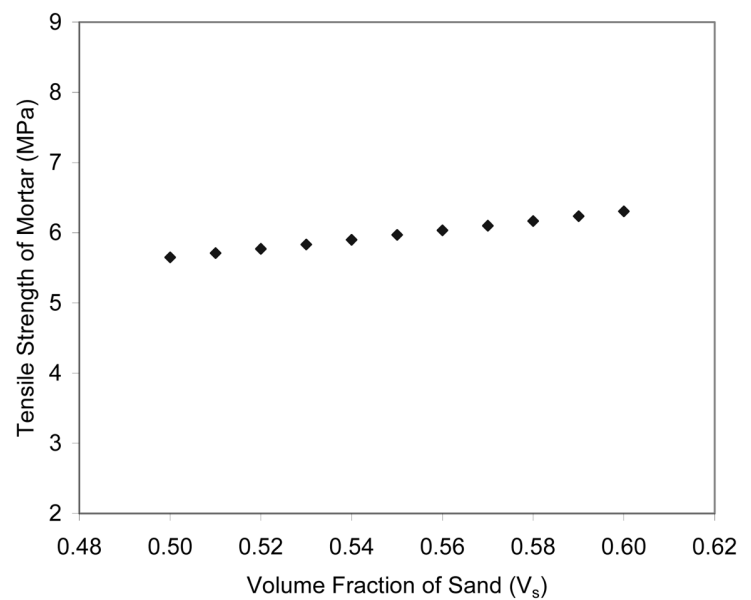

Fig. 10 Tensile strength of mortar as a function of the volume fraction of sand for a capillary porosity of 0.3 .

capillary porosity $\left(P_{h}\right)$ of 0.3 . Theoretical predications indicate a slight increase in tensile strength with increasing sand volume fraction within the range considered here. It should be noted that excess quantities of sand can compromise workability (at constant water/cement ratios), thereby complicating the production of cement mortar and thus increasing the potential for generation of large defects which are damaging to tensile strength.

\section{Conclusions}

The following conclusions can be drawn from the theoretical work presented in this paper:

1) The elastic modulus model of cement mortar was developed by considering the contributions and interactions of the hydrated cement paste, sand particles, and the ITZ. The model was further verified and refined using the experimental trends reported in the literature.

2) The fracture toughness model of cement mortar highlighted the significance of the contributions made by fine aggregates through frictional pull-out and arrest/diversion of cracks. The predictions of the fracture toughness model compared favorably with reported experimental results.

3) The tensile strength model of cement mortar was based on the corresponding elastic modulus and fracture toughness models, considering the effects of aggregates on restrained shrinkage 
microcracking of mortar. Predictions of the tensile strength model compared favorably with experimental results.

\section{References}

1. Ghebrab, T. T. and Soroushian, P., "Mechanical Properties of Hydrated Cement Paste: Development of Structure-Property Relationships," International Journal of Concrete Structures and Materials, Vol. 4, No. 1, 2010, pp. 37 43.

2. Dhir, R. K., "Key Features in View of Modeling the Permeability of Concrete," Cement Combinations for Durable Concrete Proceedings of the International Conference Held at the University of Dundee, Scotland UK, 2005, pp. 591 600.

3. Bisschop, J. and Van Mier, J. G. M., "Quantification of Shrinkage Microcracking in Young Mortar with Fluorescence Light Microscopy and ESEM," Heron, Vol. 44, No.4, 1999, pp. 245 255.

4. Scrivener, K. L., "Materials Science of Concrete I," Skalny, J. P., Ed., American Ceramic Society, 1989, pp. 127 161.

5. http://ciks.cbt.nist.gov/garbocz/104ITZ/node1.htm, 2010.

6. Hsu, T. T. C., Slate, F. O., Sturman, G. M., and Winter, G, "Microcracking of Plain Concrete and the Shape of the StressStrain Curve," American Concrete Institute Journal Proceedings, Vol. 60, No. 2, 1963, pp. 209 224.

7. Mindess, S., Young, J. F., and Darwin, D., Concrete, 2nd Ed., Prentice Hall, Pearson Education, Inc., NJ, 2003, pp. 308 311.
8. Poon, C. S., Lam, L., and Wong, Y. L., "Effects of Fly Ash and Silica Fume on Interfacial Porosity of Concrete," Journal of Materials in Civil Engineering, Vol. 11, Issue 3, 1999, pp. 197 205.

9. Mehta, P. K. and Monteiro, P. J. M., Concrete: Microstructure, Properties, and Materials, $2^{\text {nd }}$ Ed., McGraw-Hill Com. Inc., 1993.

10. Scrivener, K. L., Crumbie, A. K., and Laugesen, P., “The Interfacial Transition Zone between Cement Paste and Aggregate in Concrete," Interface Science, Vol. 12, 2004, pp. 411 421.

11. Kliszczewicz, A. and Ajdukiewicz, A., "Differences in Instantaneous Deformability of hs/hpc According to the Kind of Coarse Aggregate," Cement and Concrete Research, Vol. 24, No. 2, 2002, pp. 263 267.

12. Ramakrishnan, N. and Arunachalam, V. S., "Effective Elastic Modulus of Porous Solids," Journal of Material Science, Vol. 25, 1990, pp. 3930 3937.

13. Giaccio, G and Zerbino, R., "Failure Mechanism of Concrete: Combined Effect of Coarse Aggregates and Strength Level," Advanced Cement Based Materials, Vol. 31, 1998, pp $41 \sim 48$.

14. Liu J., Mukhopadhyay, A. K., and Zollinger, D. G., "Contribution of Aggregates to the Bonding Performance of Concrete," Paper Submitted to the Transportation Research Board for Presentation and Publication, Washington D.C., 2006. 